\title{
Распад твердого раствора межузельного магния в кремнии
}

\author{
() В.Б. Шуман ${ }^{1}$, А.Н. Лодыгин ${ }^{1}$, Л.М. Порцель ${ }^{1}$, А.А. Яковлева ${ }^{1}$, Н.В. Абросимов ${ }^{2}$, Ю.А. Астров ${ }^{1}$ \\ ${ }^{1}$ Физико-технический институт им. А.Ф. Иоффре Российской академии наук, \\ 194021 Санкт-Петербург, Россия \\ ${ }^{2}$ Leibnitz Institute for Crystal Growth, \\ 12489 Berlin, Germany \\ E-mail: a.lodygin@mail.ioffe.ru
}

(Получена 16 октября 2018 г. Принята к печати 22 октября 2018 г.)

Изучался распад твердого раствора межузельного магния $\mathrm{Mg}_{i}$ в кремнии. В опытах использовался бестигельный бездислокационный монокристаллический $n-\mathrm{Si}$ с величиной удельного сопротивления $\sim 8 \cdot 10^{3}$ Ом $\cdot$ см, содержанием кислорода $\sim 5 \cdot 10^{14} \mathrm{~cm}^{-3}$ и углерода $\sim 1 \cdot 10^{15} \mathrm{~cm}^{-3}$. Образцы легировались диффузионным сандвич-методом при $T=1100^{\circ} \mathrm{C}$ и закаливались. Распад пересыщенного твердого раствоpa $\mathrm{Mg}_{i}$ изучался путем исследования кинетики увеличения удельного сопротивления легированных образцов в результате отжигов в диапазоне $T=400-620^{\circ} \mathrm{C}$. Найдено, что процесс распада характеризуется энергией активации $E_{a} \approx 1.6$ эВ, что близко к определенной ранее энергии активации диффузии $\mathrm{Mg}_{i}$ в кремнии. Показано также, что при температурах, не превышающих $400^{\circ} \mathrm{C}, \mathrm{Si}: \mathrm{Mg}$ обнаруживает стабильные свойства, что важно при его возможном практическом использовании.

DOI: $10.21883 /$ FTP.2019.03.47280.9005

\section{1. Введение}

Примесь магния в кремнии до настоящего времени остается малоизученной, хотя первые исследования $\mathrm{Si}: \mathrm{Mg}$ были выполнены более полувека назад. Известно, что в межузельном положении в решетке кремния атом магния $\left(\mathrm{Mg}_{i}\right)$ является двойным донором $[1,2]$. В работах [2,3] с помощью оптической абсорбционной спектроскопии было обнаружено уменьшение концентрации $\mathrm{Mg}_{i}$ в образцах, хранившихся при комнатной температуре (например, после 49 месяцев хранения в $\sim 6$ раз). В работе [4] показано, что выбор особо чистых исходных материалов и оптимальной скорости охлаждения образцов после диффузионного легирования позволяет получить $\mathrm{Si}: \mathrm{Mg}$ со стабильными при комнатной температуре характеристиками.

Для практического использования магния в технологии кремния важно иметь информацию о влиянии термообработки на свойства $\mathrm{Si}: \mathrm{Mg}$. До настоящего времени систематические исследования в этой области не проводились. Цель настоящей работы - изучение изменения электрических характеристик образцов $\mathrm{Si}: \mathrm{Mg}$ в результате отжигов при различных температурах. Наряду с прикладным значением, такие исследования могут дать полезную информацию о механизме миграции $\mathrm{Mg}$ в кремнии.

\section{2. Эксперимент}

В качестве исходного материала нами использовался бездислокационный бестигельный $n$-Si кремний, выращенный в вакууме $\left(\rho_{\text {init }} \approx 8 \cdot 10^{3} \mathrm{OM} \cdot \mathrm{cm}\right.$, содержание кислорода $\sim 5 \cdot 10^{14} \mathrm{~cm}^{-3}$ и углерода $\left.\sim 1 \cdot 10^{15} \mathrm{~cm}^{-3}\right)$. Пластины кремния диаметром 30 мм и толщиной 2 мм легировались магнием чистоты 99.995\% с использова- нием сандвич-метода диффузии [1-4]. Диффузия проводилась из слоев металлического магния, который напылялся на обе стороны пластины. Процесс легирования осуществлялся в запаянных кварцевых ампулах в атмосфере аргона при $1100^{\circ} \mathrm{C}$ в течение 2.5 ч с последующим охлаждением ампулы струей сжатого воздуха. Такая процедура обеспечивала практически однородное легирование образцов по объему. В соответствии с данными измерений эффекта Холла и четырехзондового метода определения удельного сопротивления концентрация $\mathrm{Mg}_{i}$ в полученных образцах составила $N_{0} \approx 6 \cdot 10^{14} \mathrm{~cm}^{-3}$. Легированные пластины разрезались на образцы размером $10 \times 10 \times 2 \mathrm{Mм}$, которые затем подвергались ряду последовательных отжигов в вакууме в интервале $400-620^{\circ} \mathrm{C}$. Результат отжига определялся путем измерения удельного сопротивления образцов четырехзондовым методом до и после каждого отжига.

\section{3. Обсуждение результатов}

Полученные зависимости концентрации $\mathrm{Mg}_{i}$ от длительности отжига в области температур $T=400-620^{\circ} \mathrm{C}$ показаны на рис. 1. Данные представлены в виде отношения $N(t) / N_{0}$. Видно, что процесс отжига происходит в одну стадию, а отжиг при $400^{\circ} \mathrm{C}$ практически не приводит к изменению проводимости образцов.

Сплошные линии на рисунке соответствуют экспоненциальным зависимостям

$$
N(t) / N_{0}=\exp \left(-\frac{t}{\tau}\right)
$$

где $\tau-$ постоянная времени процесса распада твердого раствора $\mathrm{Mg}_{i}$ в кристаллах кремния, которая уменьшается с ростом температуры отжига. 


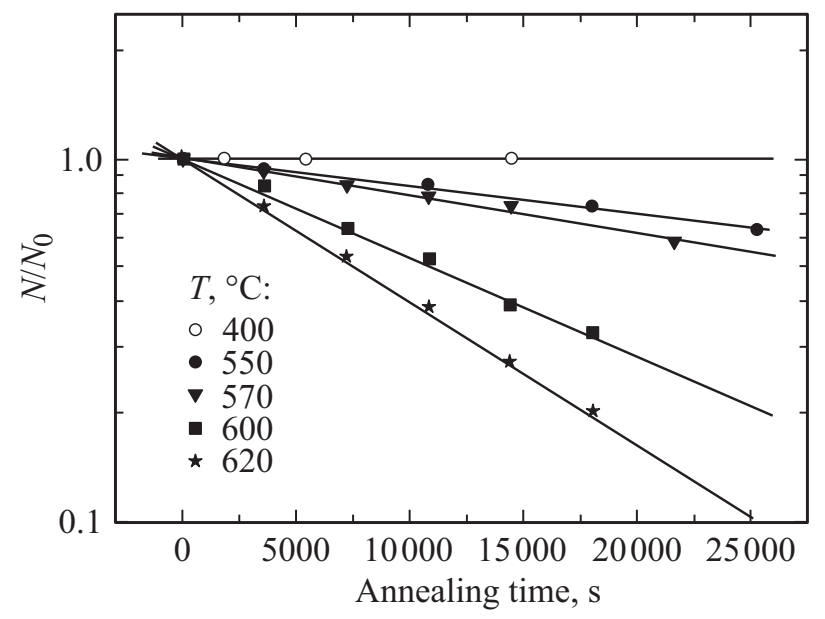

Рис. 1. Зависимости концентрации $\mathrm{Mg}_{i}$ от длительности отжига при разных температурах.

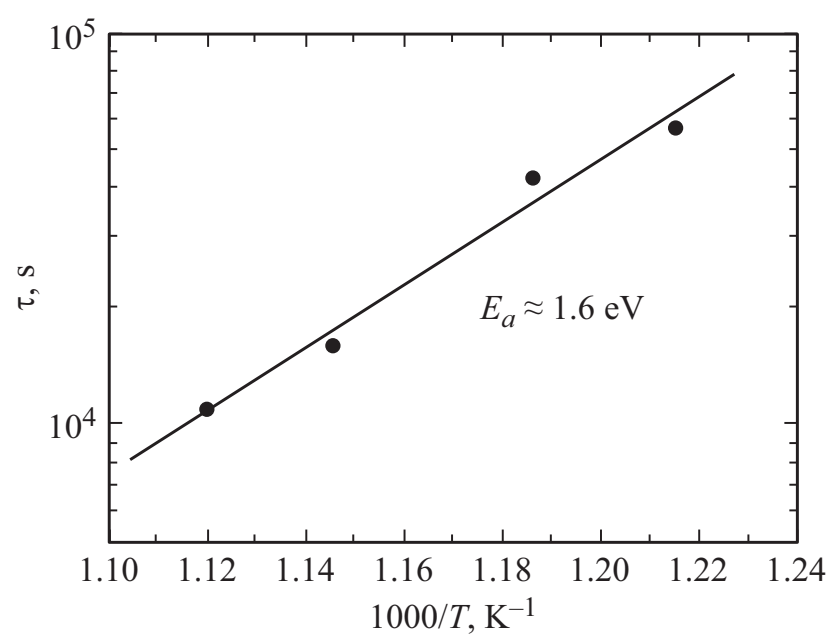

Рис. 2. Зависимость постоянной времени распада твердого раствора $\mathrm{Mg}_{i}$ в $\mathrm{Si}$ от температуры.

На рис. 2 приведена зависимость величины $\tau$ от обратной температуры отжига. Представленные в масштабе рисунка данные хорошо аппроксимируются прямой линией, что свидетельствует об активационном характере исследуемого процесса. Соответствующая энергия активации $E_{a} \approx 1.6$ эВ.

Влияние отжига на электрические характеристики $\mathrm{Si}: \mathrm{Mg}$ подобно наблюдаемому при распаде твердых растворов других быстродиффундирующих примесей в кремнии [5], а также в германии [6,7].

Можно полагать, что уменьшение концентрации донорных центров $\mathrm{Mg}_{i}$ при отжиге образцов обусловлено тем, что твердый раствор межузельного магния в решетке кремния является пересышенным в области исследованных нами температур. Пересыщение обеспечивается закалкой образцов после легирования. Полученная энергия активации процесса распада твердого раствора $\left(E_{a} \approx 1.6\right.$ эВ) близка к энергии активации диффузии $\mathrm{Mg}_{i}$ в бездислокационном кремнии, равной 1.83 эВ [4]. Отсюда можно заключить, что распад твердого раствора происходит путем диффузии примеси к центрам преципитации атомов магния (diffusion-limited annealing) [8], которые не вносят вклад в электропроводность образца. Уменьшение концентрации $\mathrm{Mg}_{i}$ может быть связано, например, с формированием частиц силицида магния или кластеров магния малого размера. Однако анализ скола исследуемых образцов в высокоразрешающем растровом электронном микроскопе не позволил выявить в них неоднородные включения.

Уже относительно давно установлено (см. фазовую диаграмму $\mathrm{Si}-\mathrm{Mg}$ в [9] для области малого содержания магния), что полная концентрация магния в легированных кристаллах может значительно, на 2 порядка величины и более, превышать соответствующее значение для $\mathrm{Mg}_{i}$. Состояние электрически неактивной примеси магния в кремнии до настоящего времени неизвестно. Подчеркнем, что приведенные нами данные касаются распада твердого раствора лишь электрически активной компоненты примеси, который можно исследовать путем измерения удельного сопротивления образцов.

\section{4. Заключение}

Из данных настоящей работы следует, что при использовании надлежащих процедур легирования и закалки электрические характеристики $\mathrm{Si}: \mathrm{Mg}$, изготовленного из кремния высокого качества, оказываются достаточно стабильными не только при комнатной температуре, но и в области температур $<400^{\circ} \mathrm{C}$. Естественно, наличие значительной концентрации неконтролируемых примесей и дефектов в кристалле может существенно ускорить распад твердого раствора $\mathrm{Mg}_{i}$ в кремнии.

Работа выполнена при поддержке программы президиума РАН № 8 ,Физика конденсированных сред и материалы нового поколения“.

\section{Список литературы}

[1] R.F. Franks, J.B. Robertson. Sol. St. Commun., 5, 479 (1967).

[2] L.T. Ho, A.K. Ramdas. Phys. Rev. B, 5, 462 (1972).

[3] L.T. Ho. Phys. Status Solidi A, 28, K73 (1975).

[4] Yu.A. Astrov, V.B. Shuman, L.M. Portsel, A.N. Lodygin, S.G. Pavlov, N.V. Abrosimov, V.N. Shastin, H.-W. Hübers. Phys. Status Solidi A, 214, 1700192 (2017).

[5] Б.И. Болтакс, М.К. Бахадырханов, С.М. Городецкий, Г.С. Куликов. Компенсированный кремний, отв. ред. Б.И. Болтакс (Л., Наука, 1972).

[6] F.P. Morin, H. Reiss. J. Chem. Sol., 3, 196 (1957).

[7] J.R. Carter, R.A. Swalin. J. Appl. Phys., 31, 1191 (1960).

[8] F.S. Ham. J. Phys. Chem. Sol., 6, 335 (1958).

[9] H. Sigmund. J. Electrochem. Soc., 129, 2809 (1982).

Редактор Г.А. Оганесян 


\section{The decomposition of the solid solution of interstitial magnesium in silicon}

V.B. Shuman ${ }^{1}$, A.N. Lodygin ${ }^{1}$, L.M. Portsel ${ }^{1}$, A.A. Yakovleva ${ }^{1}$, N.V. Abrosimov ${ }^{2}$, Yu.A. Astrov ${ }^{1}$

${ }^{1}$ loffe Institute,

194021 St. Petersburg, Russia

${ }^{2}$ Leibnitz Institute for Crystal Growth, 12489 Berlin, Germany

Abstract The decomposition of the solid solution of interstitial magnesium $\mathrm{Mg}_{i}$ in silicon is studied. In the experiments, a FZ dislocation-free silicon single-crystal $n$-Si of a resistivity of $8 \cdot 10^{3} \Omega \cdot \mathrm{cm}$ with oxygen density of $\approx 5 \cdot 10^{14} \mathrm{~cm}^{-3}$ and carbon of $\approx 1 \cdot 10^{15} \mathrm{~cm}^{-3}$ is used. The samples are doped with the „sandwich"-method of diffusion at $T=1100^{\circ} \mathrm{C}$ and then quenched. The kinetics of decomposition of the supersaturated $\mathrm{Mg}_{i}$ solid solution is investigated by observing the corresponding kinetics of an increase in the resistivity of doped samples as a result of their annealing in the range of $T=400-620^{\circ} \mathrm{C}$. It is found that the decay process is characterized by the activation energy $E_{a} \approx 1.6 \mathrm{eV}$, which is close to the previously determined activation energy of $\mathrm{Mg}_{i}$ diffusion in silicon. It is also shown that at temperatures not exceeding $400^{\circ} \mathrm{C}, \mathrm{Si}: \mathrm{Mg}$ exhibits stable properties, which is important for its possible practical use. 